\title{
Review of Adrian Dunn's The Black Messiah
}

\author{
Kennedi A. Johnson ${ }^{1}$ * \\ 1 Indiana University, USA \\ *kaj12@iu.edu \\ Received: 16 February 2021 Accepted: 23 February 2021 Published: 20 April 2021 \\ Editors: Marisol Norris, Britton Williams, Leah Gipson Reviewer: D'Angelo Virgo
}

\begin{abstract}
The Black Messiah album is a sonic meditation on Black life that confronts the histories of anti-Black racism in the U.S. Showcasing a powerful group of Black artists, the album combines multiple genres including gospel, rap, jazz and opera. The Black Messiah offers a counter to George Handel's Messiah and a timely response to the Black Lives Matter protests of summer 2020.
\end{abstract}

Adrian Dunn \& The Adrian Dunn Singers. (2020). The Black Messiah [Album]. HoperaWorld Music/Black Music Experience

While dealing with the grief and uncertainty brought on by a global pandemic, the world was also confronted with the histories and realities of anti-Black racism. We collectively heard as George Floyd called out for his mother while the life was being snuffed out of him. We read that Ahmaud Arbery was going for a jog in a neighborhood when he was pursued and killed. We watched as the police officers who shot a sleeping Breonna Taylor were acquitted of any wrongdoing.

After the inauguration of President Joseph Biden, my Facebook page seemed to be filled with people voicing their relief at a supposed return to normalcy. An understandable reaction considering the past four years under the Trump administration; however, I have always been skeptical of calls for this return.

Black death at the hands of law enforcement has been a constant in my life. Waking up, seeing yet another Black person has been murdered by police, witnessing folks bend over backwards to vilify the victim and justify their killing, and coming to grips with the fact that no one will be held accountable is my normal. Why would I, or anyone else, want to return to that? Instead of settling for the normal, why would we not want to imagine and curate a world in which Black life is cherished? A society that is unified in its quest for Black liberation? What would it look like for Black joy, grief, anger, and frustration to be centered? Composer, performer, and producer Adrian Dunn gives us an idea of what that world and society could sound like in The Black Messiah.

Both serving as a counter to George Handel's faithfully performed Messiah and responding to Black Lives Matter protests over the summer, The Black Messiah rejects calls to return to normalcy. This rejection is made clear by Dunn within the opening lines of the album's first track "Intro": "I am the person that has come to remind you 
that this year, we need to do this differently. This year, we cannot simply sing the same Christmas songs that you've sang for years before because of Breonna Taylor, Rayshard Brooks, Elijah McClain, Sandra Bland, George Floyd. All lived." He continues by telling the listener that this album serves as the "Gospel according to the Black Messiah"-a messiah in a quest for Black liberation, a messiah that recognizes the multitudes contained within the Black experience. Dunn finishes the introduction with the following: "Blackness is brilliance. Blackness is grace. Black is beautiful. Black is genius...Black is the reflection of me... Black is everything."

For the rest of the album, Dunn is accompanied by the Adrian Dunn Singers-a vocally powerful group of twelve pulled together by Dunn. Together they create a sound that cannot be confined to a singular genre. Billed as a gospel album, the sounds heard on Dunn's latest release might be considered a blend of gospel, rap, jazz, and opera. This fusion does not come as a surprise considering that Dunn, a trained opera singer, is the founder of HoperaWorld Entertainment-a production company that explores and presents the union between rap and opera.

This Hopera sound is best exemplified on the songs featuring the rapper Tony Famous, "Black Messiah" and "Rise Up." In the titular track, Famous gives voice to the Black messiah—a person who was not conceived immaculately, was raised by a single mother, and led a difficult life to be in service of the people. The Dunn Singers echo the words spoken by Famous building up to an explosive ending. "Black Messiah" is immediately followed by a more "traditional" sounding gospel song, "Behold" featuring Erica Renee. The song begins with the Singers and gradually intensifies to only fade off to make way for a beautifully performed solo by Renee. Other featured artists would include soprano Darshaya Oden and violinist Caitlin Edwards on the sweetly performed "Rejoice" and Laquentin Jenkins on the emotionally stirring "Holy." The featured artists, Dunn, and the Dunn Singers fluidly and satisfyingly move through the spectrum of Black aurality.

It should also be noted that this album is intended to be an audiovisual experience. The Black Messiah was recorded live in Chicago and can be viewed on Dunn's Black Music Experience TV (BMETV). According to the BMETV website, the company works to "amplify the narratives of Black musicians, Black culture, and justice for Black Lives" (Black Music Experience TV, n.d., para. 1). The final song of the album, "Amen," reminds us that the sentiment of honoring Black life is the heart of this very project. Dunn leaves us to reflect on these words: 'Cause you're Black. 'Cause you're loved. 'Cause you're everything. Black is everything. Amen.

The Black Messiah is a sonic meditation on Black life, loss, love, resistance, and community that folks should take time and listen to.

\section{About the Author}

Kennedi's Johnson is 4th year $\mathrm{PhD}$ student in Ethnomusicology with a $\mathrm{PhD}$ minor in African American and African Diaspora Studies at Indiana University-Bloomington. Her present interests can be broadly listed as Black feminisms, education/critical pedagogy, and sound studies. Her current research centers around the ways in which race and gender are perceived sonically in the United States. More specifically, she looks at how the (mis)hearings of Black girls/femmes as sassy, angry, or disrespectful impede their learning in the US school system.

\section{References}

Black Music Experience TV. (n.d.) About BMETV. https://blackmusicexperience.uscreen.io/ pages/about-bme. 